This document is confidential and is proprietary to the American Chemical Society and its authors. Do not copy or disclose without written permission. If you have received this item in error, notify the sender and delete all copies.

\title{
Supramolecular Spangling, Crocheting and Knitting of Functionalized Pyrene Molecules on a Silver Surface
}

\begin{tabular}{|r|l|}
\hline \multicolumn{1}{|c|}{ Journal: } & ACS Nano \\
\hline Manuscript ID & nn-2016-02989e.R1 \\
\hline Manuscript Type: & Article \\
\hline Date Submitted by the Author: & $\mathrm{n} / \mathrm{a}$ \\
\hline Complete List of Authors: & $\begin{array}{l}\text { Kaposi, Tobias; Technical University Munich } \\
\text { Joshi, Sushobhan; Technical University Munich } \\
\text { Hoh, Tobias; Technical University Munich } \\
\text { Wiengarten, Alissa; Technical University Munich } \\
\text { Seufert, Knud; Technical University Munich } \\
\text { Paszkiewicz, Mateusz; Technical University Munich } \\
\text { Klappenberger, Florian; Technical University Munich } \\
\text { Ecija, David; Technical University Munich } \\
\text { Đorđević, Luka; Universita degli Studi di Trieste, Department of Chemistry } \\
\text { Marangoni, Tomas; University of Trieste } \\
\text { Bonifazi, Davide; Cardiff University, Organic Supramolecular Chemistry } \\
\text { Barth, Johannes; Technical University Munich } \\
\text { Auwärter, Willi; Technical University Munich, }\end{array}$ \\
\hline
\end{tabular}

\section{SCHOLARONE}

Manuscripts 


\title{
Supramolecular Spangling, Crocheting and Knitting
}

\section{of Functionalized Pyrene Molecules on a Silver}

\section{Surface}

\author{
Tobias Kaposi,,$^{\dagger}$ Sushobhan Joshi, ${ }^{\dagger}$ Tobias Hoh,,$^{\dagger}$ Alissa Wiengarten, ${ }^{\dagger}$ Knud Seufert,,$^{\dagger}$ Matheusz \\ Paszkiewicz, ${ }^{\dagger}$ Florian Klappenberger, ${ }^{\dagger}$ David Ecija, ${ }^{\dagger} *$ Luka Đorđevic,,$^{\S}$ Tomas Marangoni, ${ }^{\S}$ \\ Davide Bonifazi, ${ }^{\S,}{ }^{+} *$ Johannes V. Barth ${ }^{\dagger}$ and Willi Auwärter, ${ }^{\dagger} *$ \\ † Physik-Department E20, Technische Universität München, D-85748 Garching, Germany \\ $\S$ Department of Chemical and Pharmaceutical Sciences, INSTM UdR Trieste, University of \\ Trieste, Piazzale Europa 1, 34127 Trieste, Italy
}

$\perp$ School of Chemistry; Cardiff University, Park Place, CF10 3AT, Cardiff, United Kingdom.

\begin{abstract}
KEYWORDS: supramolecular chemistry, surface science, pyrene, host-guest systems on surfaces, polycyclic aromatic hydrocarbons, halogens, scanning tunneling microscopy, x-ray photoelectron spectroscopy
\end{abstract}


ABSTRACT: Pyrenes, as photoactive polycyclic aromatic hydrocarbons (PAHs), represent promising modules for the bottom-up assembly of functional nanostructures. Here, we introduce the synthesis of a new family of pyrene derivatives peripherally functionalized with pyridin-4ylethynyl termini and comprehensively characterize their self-assembly abilities on a smooth $\operatorname{Ag}(111)$ support by scanning tunneling microscopy. By deliberate selection of number and geometric positioning of the pyridyl-terminated substituents, two-dimensional arrays, onedimensional coordination chains and chiral, porous kagomé-type networks can be tailored. A comparison to phenyl-functionalized reference pyrenes, not supporting the self-assembly of ordered structures at low coverage, highlights the role of the pyridyl moieties for the supramolecular crocheting and knitting. Furthermore, we demonstrate the selective spangling of pores in the two-dimensional pyrene assemblies by a distinct number of iodine atoms as guests by atomically resolved imaging and complementary X-ray photoelectron spectroscopy.

Design of materials for manufacturing molecular-based devices still remains a challenge because of the difficulty to precisely control and manipulate the spatial organization at the molecular level. ${ }^{1-4}$ In this respect, the non-covalent molecular self-assembly ${ }^{5-7}$ into ordered domains is a very promising methodology for the construction of molecularly organized materials at interfaces since, in principle, it permits the controlled, large scale formation and precise positioning of functional molecules with respect to each other. ${ }^{8-15}$ Moreover, scanning probe techniques ${ }^{16}$ have been particularly useful in studying the self-assembly of molecules on metallic and insulating single crystal surfaces, yielding model systems for investigating molecular reactivity ${ }^{17-18}$ and catalytic behavior, ${ }^{19-20}$ nano-patterning, ${ }^{11}$ charge-transfer processes $^{21}$ and reaction mechanisms ${ }^{22}$ to name a few. 
In recent years, our groups and others have shown that programming organic molecules, through an appropriate geometrical combination of different peripheral recognition moieties, allows the formation of nanostructured surfaces featuring different architectures with various shapes and dimensions. ${ }^{23-28}$ For example, exploiting the aptitude of pyridyl and cyanophenyl groups to engage in H-bonding, dipole-dipole or metal coordination interactions interactions, ${ }^{29-33}$ functional porphyrin derivatives ${ }^{34-35}$ featuring programmed geometries could be selectively organized in the presence of metal atoms as supramolecular polymers, ${ }^{36}$ discrete macrocycles ${ }^{37}$ or arrays with one ${ }^{38}$ or two metal atoms. ${ }^{31}$ In this context, photoactive polycyclic aromatic hydrocarbons (PAHs) are also of great interest due to their relevance in molecular electronics and photovoltaics. ${ }^{39-41}$ Among the different PAHs, pyrene derivatives ${ }^{42}$ have yet again renewed the interest of the scientific community as they constitute a suitable class of functional molecules for engineering optoelectronic devices ${ }^{43-44}$ due to their synthetic versatility ${ }^{42,45-46}$ and strong emissive properties ${ }^{42,}{ }^{47}$ Specific pyrene functionalizations were introduced to promote their self-assembly abilities and to tailor the interaction with carbon supports in solution, including nanotubes, graphene and HOPG. ${ }^{48-50}$ E.g., it has been shown that 1,3,6,8-tetrasubstituted pyrenyl-based modules exposing lateral H-bonding recognition motifs provided unambiguous evidence for the formation of multicomponent H-bonded 2D polygonal assemblies (e.g. triangles) at the solid-liquid interface on $\mathrm{HOPG},{ }^{51-52}$ the organization of which is solely controlled by the molecular geometry. Strikingly, reports exploring the self-assembly of functionalized pyrenes in a controlled ultra-high vacuum (UHV) environment are very scarce ${ }^{53-54}$ and mainly restricted to halogenated pyrene cores that might engage in H-bonding, halogenbonding, organo-metallic and covalent interactions. ${ }^{50,55}$ Thus, the pyrene assemblies reported to date consist of either dense-packed arrays or disordered networks. In this study, we address for 
the first time a systematic tailoring of low-dimensional supramolecular architectures in UHV via pyrene functionalization.

\section{RESULTS AND DISCUSSION}

Here, we present the synthesis and systematic UHV low-temperature scanning tunneling microscopy (STM) study of a family of pyrene derivatives peripherally functionalized with ethynylpyrid-4-yl (1-3) termini. The possibility to selectively functionalize the pyrene core with semi-flexible coordinating fragments (derivatives 1-3) gave the option to obtain molecular modules in which the pyridyl recognition sites are geometrically positioned at different angles with respect to each other. Specifically, 1,3,6,8-tetradentate derivative 1, which bears four pyridin-4-ylethynyl units, possesses two different angles between the recognition fragments, namely $60^{\circ}$ ("longitudinal" relative positions) and $120^{\circ}$ ("latitudinal" relative position). In the case of the bis-substituted derivatives, it is possible to position the recognition unit exclusively at $180^{\circ}$ (equatorial position, 2) or at $60^{\circ}$ (longitudinal position, 3). Differently from our previous reports on assemblies based on the pyridyl-metal-pyridyl coordination motifs, ${ }^{36,56}$ the overall molecular structure of the aromatic core has been maintained completely planar avoiding the introduction of bulky alkylic groups. Driven by $\mathrm{N}^{\cdots} \mathrm{H}$ bonding interactions, the molecules undergo the formation of different supramolecular patterns, the structure of which revealed to be controlled by the molecular geometry and the number of the pyridin-4-ylethynyl substituents. Reference phenylethynyl-substituted pyrenes (1a-3a) have been also prepared, these displaying a peculiar non-collective behavior, where distributed single molecular units are observed on the $\operatorname{Ag}(111)$ surface at low coverage. 

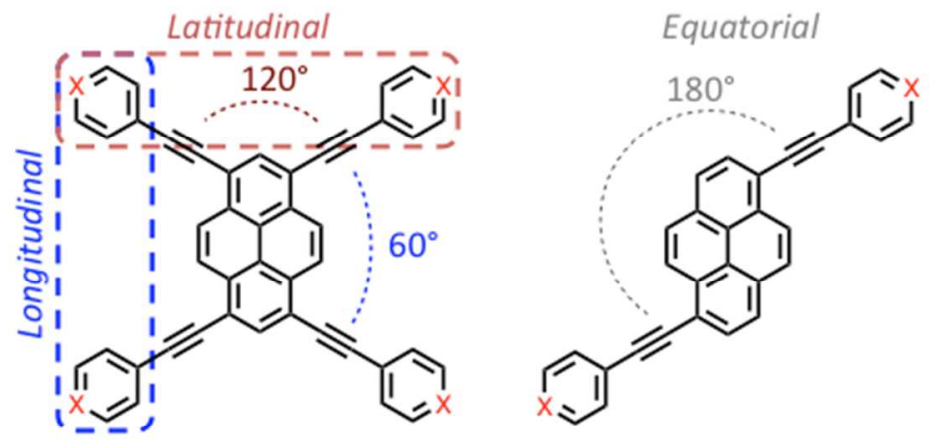

Longitudinal

$$
\begin{aligned}
& 1 \quad X=N \\
& \text { 1a } \mathrm{X}=\mathrm{CH}
\end{aligned}
$$

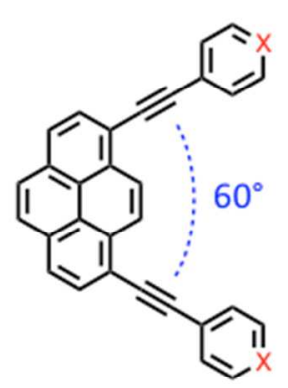

$$
\begin{array}{ll}
2 & X=N \\
\text { 2a } & X=C H
\end{array}
$$

Figure 1. Functionalized pyrenyl modules studied in this work. $X=N$ and $X=C-H$ for the pyridyl- (1-3) and phenyl-derived (1a-3a) modules, respectively.

\section{Synthesis}

The complete synthetic approach is depicted in Scheme 1. Starting from commercially available pyrene, different conditions were employed to introduce a number of halogen atoms at pre-designed positions. For example, following literature conditions, ${ }^{57-59}$ exhaustive bromination of the pyrene moiety in the presence of $\mathrm{Br}_{2}$ in nitrobenzene at $120{ }^{\circ} \mathrm{C}$ afforded $1,3,7,8-$ tetrabromopyrene 4 . Notably, to obtain 1,6- and 1,8-disubstituted pyrenes 6 and 8 , halogenation reactions with $\mathrm{Br}_{2}$ in $\mathrm{CCl}_{4}$ at room temperature or with $\mathrm{I}_{2}$ and $\mathrm{KIO}_{4}$ in $\mathrm{H}_{2} \mathrm{SO}_{4}$ and $\mathrm{CH}_{3} \mathrm{COOH}$ at $40{ }^{\circ} \mathrm{C}$ were used. Both 1,6-dibromopyrene and 1,8-diiodopyrene could be isolated as pure products crystallization. The halogen-derived pyrenes were subjected to Sonogashira-Hagihara Pd-catalyzed cross-coupling reaction ${ }^{60-61}$ to obtain the relevant TMS-protected ethynyl derivatives, that in the presence of a $\mathrm{KOH}$ solution in $\mathrm{MeOH} / \mathrm{THF}$ (1:1) could be deprotected leading to the terminal acetylene derivatives $\left(\mathbf{5}, 7\right.$ and 9) ${ }^{51}$ Subsequent Sonogashira-Hagihara cross coupling with 4-iodopyridine or iodobenzene afforded ligands 1-3 and reference molecule 1a-3a in good yields (Scheme 1). Whereas the introduction of the phenyl groups did not pose 
particular challenges (compounds 1a-3a), equipping the pyrene core with the pyridyl moieties proved to be particularly challenging because of the significant insolubility of final conjugates $\mathbf{1}$ and $\mathbf{2}$ in classical organic solvents. Compound $\mathbf{2}$, with the two pyridyl moieties in position 1 and 8, had a sufficient solubility in pyridine, which allowed its purification by column chromatography. On the other hand, compounds $\mathbf{1}$ and $\mathbf{2}$ were prepared in two different methods: i) following conventional protocols ${ }^{60,} 62$ with $\mathrm{Pd}$ catalyst and $\mathrm{CuI}$ as co-catalyst at room temperature and ii) microwave assisted conditions. While classical conditions afforded precipitates within minutes from the onset of the reaction (that was extensively washed with $\mathrm{MeOH}$, AcCN and toluene) that were hardly processable in common organic solvents, microwave irradiation conditions yielded more soluble (i.e., most likely less aggregated) materials soluble in organic solvents at high temperatures (e.g., 1,1,2,2-tetrachloroethane, TCE). Accordingly, it was possible to obtain different materials that were subsequently sublimed on $\operatorname{Ag}(111)$ : classical conditions yielded pyrene derivatives $\mathbf{1}$ and $\mathbf{2}$ contaminated with iodide species, presumably from $\mathrm{CuI}$ as co-catalyst, and microwave assisted reaction yielded uncontaminated molecules 1-3 that were thoroughly characterized (see Supporting Information (SI)).

Scheme 1. Synthetic pathways for the preparation of compounds 1-9. 


\section{Self-assembly on $\operatorname{Ag}(111)$}

The deposition of a submonolayer coverage of tetrapyridyl pyrene derivative 1 on $\operatorname{Ag}(111)$ gives rise to the formation of regular, extended islands (Figure 2a), presenting one border always pinned to the bottom side of crystal step edges, which hints to their role as nucleation centers. High-resolution STM data (Figure 2b) reveals the layer organization and submolecular features. Each molecule exhibits a two-fold symmetric shape resembling a St. Andrew's cross, suggesting a flat adsorption on the surface, with a bright central core, attributed to the pyrene core, and four peripheral, dim circular lobes, assigned to the peripheral pyridin-4-ylethynyl functional groups. 

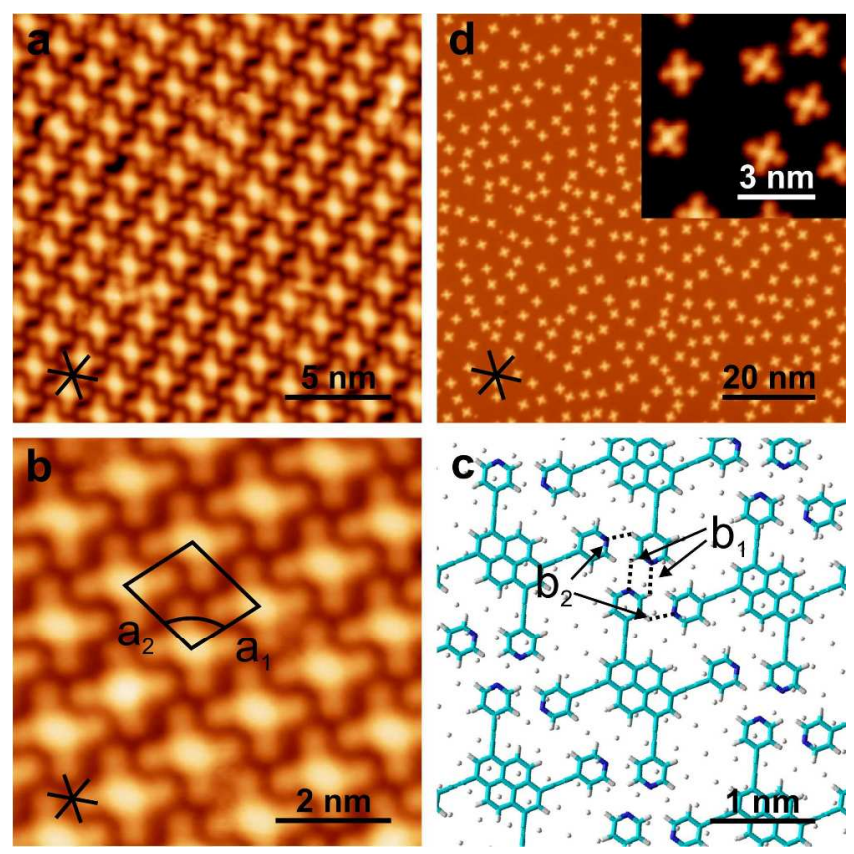

Figure 2. Self-assembled network of tetrapyridyl pyrene 1 on $\operatorname{Ag}(111)$ as imaged by STM. (a-c) Tetrapyridylpyrene species on $\mathrm{Ag}(111)$. (a) Overview image (0.1 nA, -0.2 V). (b) Highresolution image displaying the supramolecular assembly with a rhombic unit cell (black lines, lattice vectors $a_{1}$ and $a_{2} .0 .1 \mathrm{nA},-0.5 \mathrm{~V}$ ). (c) Structural model. Dashed lines indicate $\mathrm{N}^{\cdots} \mathrm{H}$ interactions with tow projected bond distances $b_{1}$ and $b_{2}$. (d) Tetraphenyl species 1a on $\operatorname{Ag}(111)$ : overview $(0.5 \mathrm{nA}, 1 \mathrm{~V})$ and high-resolution insert $(0.2 \mathrm{nA}, 0.1 \mathrm{~V})$. The stars indicate the densepacked directions of the $\operatorname{Ag}(111)$ lattice.

The molecules are arranged forming a rhombic network defined by the lattice vectors $\mathbf{a}_{1}=15.4$ $\pm 0.5 \AA$ and $\mathbf{a}_{2}=18.0 \pm 0.5 \AA$, with an opening angle $\gamma$ equal to $100 \pm 2^{\circ}$ (cf. black rhombus in figure $2 \mathrm{~b}$ ). As a result, molecules 1 interdigitate in the short direction $\mathrm{a}_{1}$, whereas they form a small rhombic cavity of approximately $6 \times 6 \AA^{2}$ along direction $a_{2}$. A tentative atomistic model of the assembly is depicted in Figure 2c. Within the accuracy of the STM calibration, the architecture appears as a superstructure semi-commensurate with the $\operatorname{Ag}(111)$ substrate with matrix: ${ }^{63}$ 


$$
M=\left(\begin{array}{cc}
4.5 & 1.5 \\
\overline{4} & 7
\end{array}\right)
$$

Although the exact binding site cannot be determined from this model, it becomes apparent that every row in $\mathrm{a}_{2}$-direction consists of molecules adsorbed on identical binding sites, with binding sites alternating between the rows aligned along the $a_{1}$-direction. The majority of molecules aligns their short axis of symmetry slightly off the close-packed directions of the $\operatorname{Ag}(111)$ lattice (cf. Figure 2b, c). Within one island the pyrene molecules present the same orientation. The rhombic network is mainly stabilized by two distinct intermolecular noncovalent $\mathrm{N}^{\cdots} \mathrm{H}$ bonds (indicated $a \mathrm{~b}_{1}$ and $\mathrm{b}_{2}$ in figure $2 \mathrm{c}$ ) between the pyridyl functions of adjacent species, with projected $\mathrm{N}^{\cdots} \mathrm{H}$ lengths of $3.1 \pm 0.3 \AA$ and $2.6 \pm 0.3 \AA$, respectively. Notably, the domains present organizational chirality based on two distinct interdigitation alignments of the achiral pyrene units. Accordingly, mirror domains of derivative $\mathbf{1}$ are resolved on the surface (SI Figure SI1). A very similar array structure stabilized by $\mathrm{N}^{\cdots} \mathrm{H}$ bonds is achieved on a hexagonal boron nitride $(h$-BN) monolayer on $\mathrm{Cu}(111)$ (SI Figure SI2).

To elucidate the relevance of the pyridine-4-ylethynyl groups, reference tetraphenyl pyrene derivative 1a (1,3,6,8-tetra(phenylethynyl)pyrene) was also deposited on $\operatorname{Ag}(111)$ (Figure 2d). Although the molecules adsorb flat on the surface as pyrene derivative $\mathbf{1}$, the absence of the peripheral pyridyl groups prevents the formation of $\mathrm{N}^{\cdots} \mathrm{H}$ bonds and, despite the possibility of aggregating through VdW interactions, only a scattered distribution of molecules 1a is clearly observed on the surface. Statistical analysis of next-neighbor distances does not reveal counts at a separation closer than $20 \AA$ (cf. right panel of Figure SI3). This suggests the presence of considerable intermolecular repulsion, possibly caused by molecule-substrate charge transfer. ${ }^{53}$, 64-66 
Molecule 1a also aligns its short symmetry axis slightly off to the close-packed directions of the $\operatorname{Ag}(111)$ lattice, similarly to derivative 1 . The effect is small (about $5^{\circ}$ ), but comparable for both cases. This suggests that the tilt is primarily induced by interactions between the surface and pyrene core rather than intermolecular interactions through the pyridyl moieties.

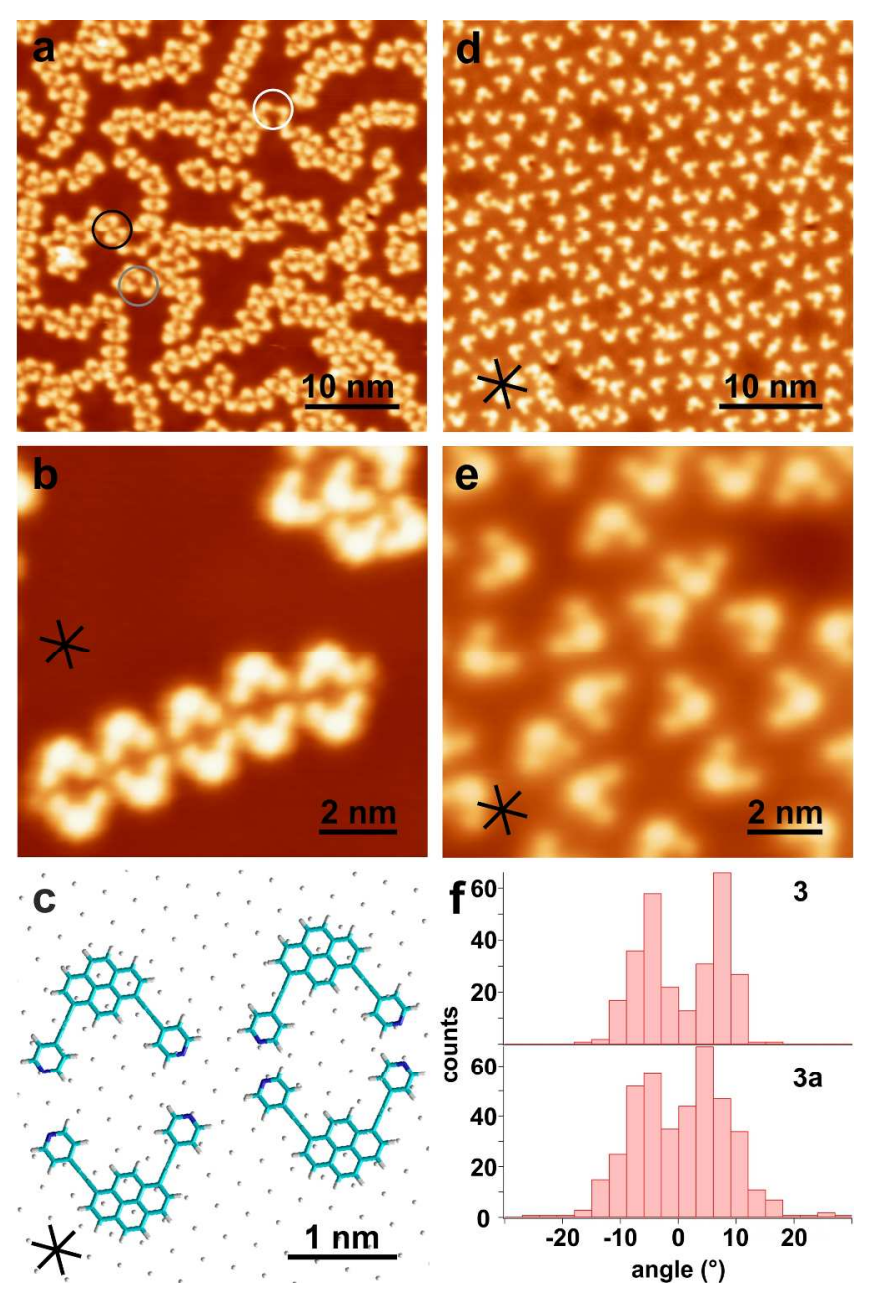

Figure 3. Self-assembly of cis-like bidentate pyrene modules $\mathbf{3}$ and $\mathbf{3 a}$ on $\operatorname{Ag}(111)$. (a-c) cis-like dipyridyl-pyrene 3 on $\operatorname{Ag}(111)$. a) Overview image (0.1 nA, -0.2 V). The circles highlight nodes of different symmetries (see text). (b) High-resolution image (0.15 nA, $-0.2 \mathrm{~V})$. (c) Structural model showing two dimer configurations on the $\operatorname{Ag}(111)$ lattice. The projected $\mathrm{N}^{\cdots} \mathrm{N}$ distances are $3.7 \AA$ and $4.8 \AA$, respectively. (d-e) cis-like diphenyl-pyrene 3a on $\operatorname{Ag}(111)$. (d) Overview image $(0.09 \mathrm{nA}, 0.1 \mathrm{~V})$. No assemblies are formed after room temperature deposition of 
reference species 3a. (e) High-resolution image of 3a highlighting the restricted number of orientations of the molecule on the $\operatorname{Ag}(111)$ lattice $(0.1 \mathrm{nA}, 0.1 \mathrm{~V})$. (f) Histograms showing the distribution of angular alignment deviation from close-packed lattice directions (equivalent to $0^{\circ}$ ) for molecules $\mathbf{3}$ and $\mathbf{3 a}$ (406 and 275 molecules, respectively).

Next, the focus was set on the self-assembly of di-substituted pyrene derivatives 2-2a and 33a. 1,6-di(pyridin-4-ylethynyl)pyrene (referred to as cis-like dipyridyl-pyrene) derivative 3 was sublimated on pristine $\operatorname{Ag}(111)$. Figure 3a displays the resulting assembly for a submonolayer coverage, which consists of long chains, coexisting with some disordered two-dimensional agglomerates. A high-resolution image allows us to discern the submolecular features (Figure 3b). Each molecule presents a two-fold V-like shape, exhibiting a bright protrusion attributed to the pyrene core, and two dim peripheral lobes assigned to the pyridin-4-ylethynyl groups. Regarding the molecular organization, two supramolecular motifs are clearly identified: i) headto-head contacts between oppositely oriented species, giving rise to chains (cf. bottom part of figure $3 \mathrm{~b}$ ) and ii) intermolecular $\mathrm{N}^{\cdots} \mathrm{H}$ bonds between pyridin-4-ylethynyl moieties and the pyrene core of adjacent molecules with a projected $\mathrm{N}^{\cdots} \mathrm{H}$ length of $2.3 \pm 0.5 \AA$, giving rise to the formation of agglomerates (cf. top part of Figure 3b). A tentative atomistic model of the molecular chains is depicted in Figure 3c, revealing a non-commensurate adsorption of the molecular species. Again, the axis of symmetry is oriented slightly off the close-packed directions of the substrate. The nature of the head-to-head contacts (motif i) is still under debate and may involve Ag substrate atoms, probably slightly pulled up by the interaction with the pyridyl moieties. ${ }^{67}$ A statistical analysis of nearest neighbor separations for a coverage of 0.23 molecules $/ \mathrm{nm}^{2}$ reveals a preferred separation of $15 \AA$ (cf. left panel of Figure SI3) that is shorter than the head-to-head distance of roughly $18 \AA$ and thus bases on neighbors along the curved 
chains. Besides the regular chains segments where four pyridyl termini of adjacent pyrene pairs meet in a four-fold node (cf. black circle in Figure 3b), three-fold (grey circle) and two-fold (white circle) pyridyl arrangements are observed, introducing some disorder in the chains.

As in the assembly of species 1a, the deposition of bidentate cis-diphenyl-pyrene species 3a on $\operatorname{Ag}(111)$ results in a scattered distribution of molecules over the entire surface (Figure $3 \mathrm{~d}, \mathrm{e})$. High-resolution STM images show that this molecular species presents a very similar appearance to $\mathbf{3}$, i.e. they are adsorbed flat exhibiting a central bright core attributed to the pyrene backbone, and two peripheral dim lobes assigned to the phenyl functions. A statistical analysis of the nearest neighbor separations for coverage of 0.18 molecules $/ \mathrm{nm}^{2}$ (cf. middle panel in Figure SI3) reveals the absence of counts at small separations, pointing to a dominating repulsive moleculemolecule interaction, possibly originating from molecule-substrate charge transfer. ${ }^{53}$ In addition, a statistical analysis was made pertaining to the orientation of modules $\mathbf{3}$ and $\mathbf{3 a}$ with respect to dense-packed lattice directions, which shows that both species tend to prefer a slightly tilted orientation of their short symmetry axis of about $5-10^{\circ}$ off the closest high-symmetry direction (cf. Figure $3 \mathrm{f}$ and model in $3 \mathrm{c}$ for comparison). This is in agreement with the distribution of orientations for pyrene module 1a, corroborating our assumption that the substrate-backbone interactions rather than the interactions between substrate and functional groups are governing the alignment. However, the distribution is slightly narrower in the case of phenyl-terminated module 3a. We attribute this to a directional influence due to interactions between the pyridyl nitrogen atom and the surface, stabilizing the molecule in orientations with even bigger misalignment with respect to the dense-packed crystal directions. The rather narrow distribution of misalignments leads to an almost uniform distribution of chain orientations for low coverages of pyrene derivative 3. This is in contrast with other systems where a more rigid alignment 


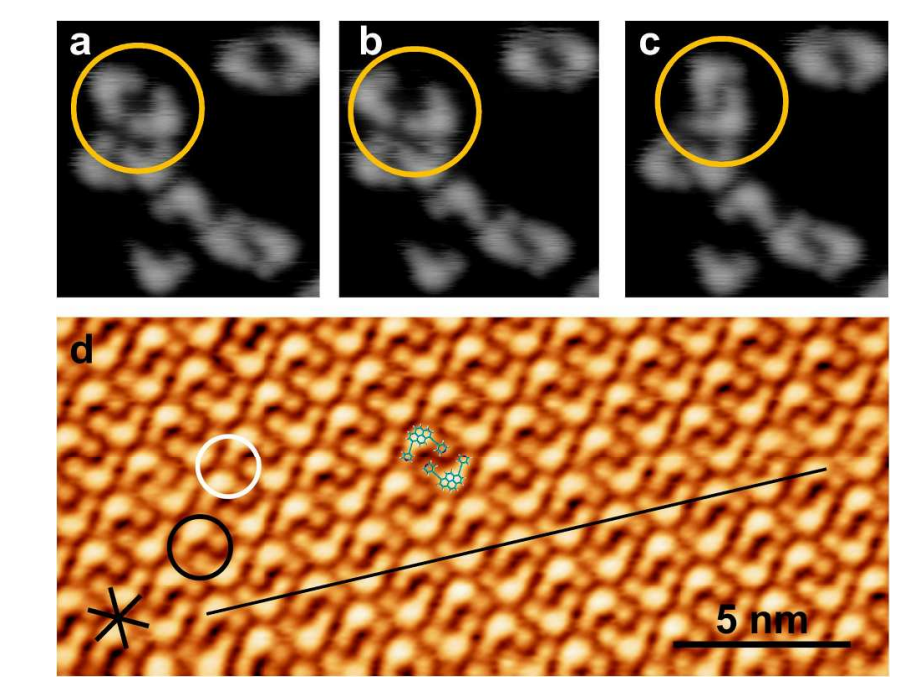

between neighboring molecules corresponds to directionality in the assembly of one-dimensional structures. $^{36}$

Remarkably, as depicted in Figures 4a-c, by lateral STM manipulation of a head-to-head link of cis-like pyrene $\mathbf{3}$ one can reversibly convert the motif into an interdigitated dimeric complex (Figure 4c) with a separation of $15 \AA$, which involves $\mathrm{N}^{\cdots} \mathrm{H}$ bonds between opposite molecular units.

Figure 4. Meta-stability of the head-to-head coupling of cis-like pyrene 3 on $\operatorname{Ag}(111)$. Transformation of the head-to-head motif (a) to a dense-packed dimer (c) by lateral STM manipulation at $6 \mathrm{~K}$. This process is reversible $(0.08 \mathrm{nA},-1 \mathrm{~V})$. (d) An identical packing is achieved at a full coverage of the sample after room temperature deposition $(0.1 \mathrm{nA}, 0.1 \mathrm{~V})$. The superimposed models represent the dimer motif.

By drastically increasing the coverage up to the monolayer regime, a new phase arises (Figure 4d), which presents a one-dimensional long-range order and consists of parallel rows of two oppositely oriented molecules (cf. black line superimposed on a row in figure 4d). The rows are interlocked with each other by two different $\mathrm{N} \cdots \mathrm{H}$ H-bonds: i) the interdigitated dimer described 
above (cf. black circle in figure 4d), and ii) that between the pyridin-4-ylethynyl moieties and the pyrene core of identically-oriented species (cf. white circle in Figure 4d). Again, as a result of the interdigitated dimer, a surface organizational chirality arises in the form of two different synthons. This duality in turn gives rise to two possible domains within the dense-packed, “crocheted" arrays (Figure 4d just above the black line).

In a further set of experiments, the sublimation of trans-like dipyridyl-pyrene derivative $\mathbf{2}$ on $\mathrm{Ag}(111)$ gives rise to a porous network, featuring a kagomé lattice architecture. ${ }^{68-70}$ An overview image is presented in Figure 5a, exhibiting cavities of two different diameters, about 6 and $18 \AA$, respectively. A high-resolution image allows us to discern certain intramolecular features (Figure $5 b)$ in this intricate lattice, reminiscent of a knitted mesh. The molecular species exhibit a bright central lobe and two peripheral dims, again assigned to the pyrene core and pyridin-4-ylethynyl moieties, respectively.
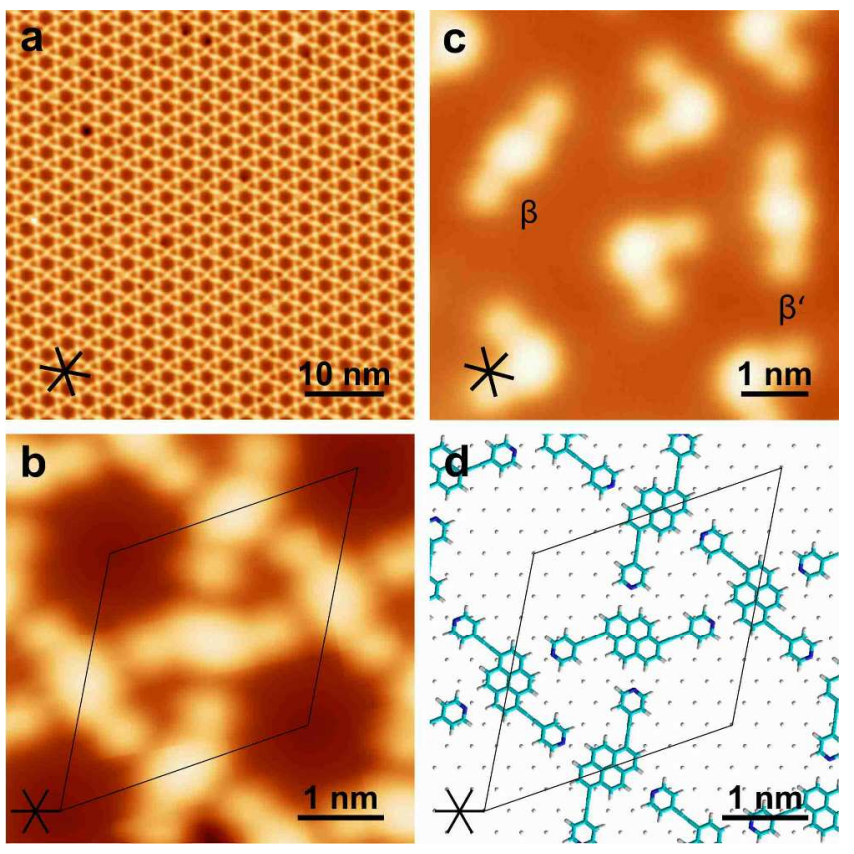
Figure 5. Self-assembly of trans-like bidentated pyrenes 2 and $\mathbf{2 a}$ on $\operatorname{Ag}(111)$. (a,b) Kagomé lattice formed by molecule 2. (a) Overview image $(0.1 \mathrm{nA},-0.2 \mathrm{~V})$. (b) High-resolution image $(0.5 \mathrm{nA},-0.02 \mathrm{~V})$ and superimposed unit cell of the kagomé lattice formed by $\mathbf{2}$. (c) Individual $\mathbf{2 a}$ and 3a reference molecules coexisting on $\operatorname{Ag}(111)(0.09 \mathrm{nA}, 0.1 \mathrm{~V})$. (d) Structural model of the kagomé lattice and its unit cell.

Furthermore, since the trans-like isomers have prochiral faces, a specific molecular chirality is exhibited upon adsorption on the metal surface. Hence, the supramolecular network features a chiral arrangement, which manifests in the presence of two enantiopure mirror-symmetric domains of the kagomé network, designated as $\alpha$-trans and $\alpha^{\prime}$-trans (see SI Figure SI4). A tentative structural model reveals commensurability of both domains with the underlying substrate within the accuracy of the STM calibration (Figure 5d). In this model the unit-cell vectors of the kagomé lattice $\left(a_{1}=a_{2}=30.6 \AA\right)$ form an angle of $\pm 19.1^{\circ}$ (negative for $\alpha$-trans, positive for $\alpha^{\prime}$-trans) with respect to the close-packed directions of $\operatorname{Ag}(111)$. The model geometry is a perfect hexagonal lattice with an inscribed angle of $60^{\circ}$ between $a_{1}$ and $a_{2}$, the superstructure can thus be designated as $(\sqrt{ } 112 \times \sqrt{ } 112) R 19.1^{\circ}$. Again, the formation of this network is glued by intermolecular $\mathrm{N} \cdots \mathrm{H}$ H-bonds between pyridyl ligands and adjacent pyrene cores, with a projected $\mathrm{N} \cdots \mathrm{H}$ bond length of $(2.7 \pm 0.5) \AA$. These interactions along with the commensurability lead to the formation of highly regular and extended islands, some of which were found to exceed an area of $0.2 \mu \mathrm{m}^{2}$.

Finally, trans-like diphenyl-pyrene derivative 2a presents a uniform distribution of single molecules on the $\operatorname{Ag}(111)$ surface, again suggesting the presence of repulsive intermolecular interactions. For comparison purposes, Figure 5c shows both molecules of $\mathbf{2 a}$ and 3a. Trans-like 
pyrenes $\mathbf{2 a}$ are adsorbed flat on the surface and exhibit similar appearance to that of molecule $\mathbf{2}$, presenting a central bright lobe identified as the pyrene core and two peripheral features attributed to the phenyl substituents. Since the molecule also possesses two prochiral faces, two different chiral adsorption modes have been found and labeled as $\beta$-trans and $\beta$ '-trans, respectively, (see Figure 5c).

\section{Iodine co-adsorption}

To explore the hosting capabilities of the porous pyrene networks to monoatomic adsorbates, we analyzed samples of molecules $\mathbf{1}$ and $\mathbf{2}$ containing iodide contaminations. Halogens, and specifically the elements iodine and bromine, currently attract considerable interest in selfassembly procedures as halogen-bonds ${ }^{71-72}$ can lead to the formation of surface-anchored molecular networks on the one hand, ${ }^{73-74}$ on the other hand halogen-containing byproducts are formed during surface confined Ullmann coupling. ${ }^{75-77}$

Indeed, after depositing iodine-containing species $\mathbf{1}$ and $\mathbf{2}$ we found a majority of the cavities formed by the supra-molecular networks to be spangled by circular protrusions (Figure 6), in brightness and thus apparent height similar to the surrounding molecules. The apparent extension of the protrusions in STM images is consistent with single iodine species. Indeed, XPS experiments yielding chemical sensitivity allow us to conclusively assign these protrusions to adsorbed iodine atoms interacting with Ag, i.e., to iodide species (Figure 6f). In the iodine $3 \mathrm{~d}$ XP spectra, recorded after depositing a layer of the iodine-containing tetra-pyridyl-pyrene batch on $\operatorname{Ag}(111)$, one can clearly observe two signals, reflecting the spin-orbit split $3 \mathrm{~d}_{5 / 2}$ and $3 \mathrm{~d}_{3 / 2}$ components. The most intense feature with binding energy of $618.6 \mathrm{eV}$ corresponds to the $3 \mathrm{~d}_{5 / 2}$ orbital while the second one is attributed to the $3 \mathrm{~d}_{3 / 2}$ orbital with a binding energy of $630.1 \mathrm{eV}^{78-}$ 

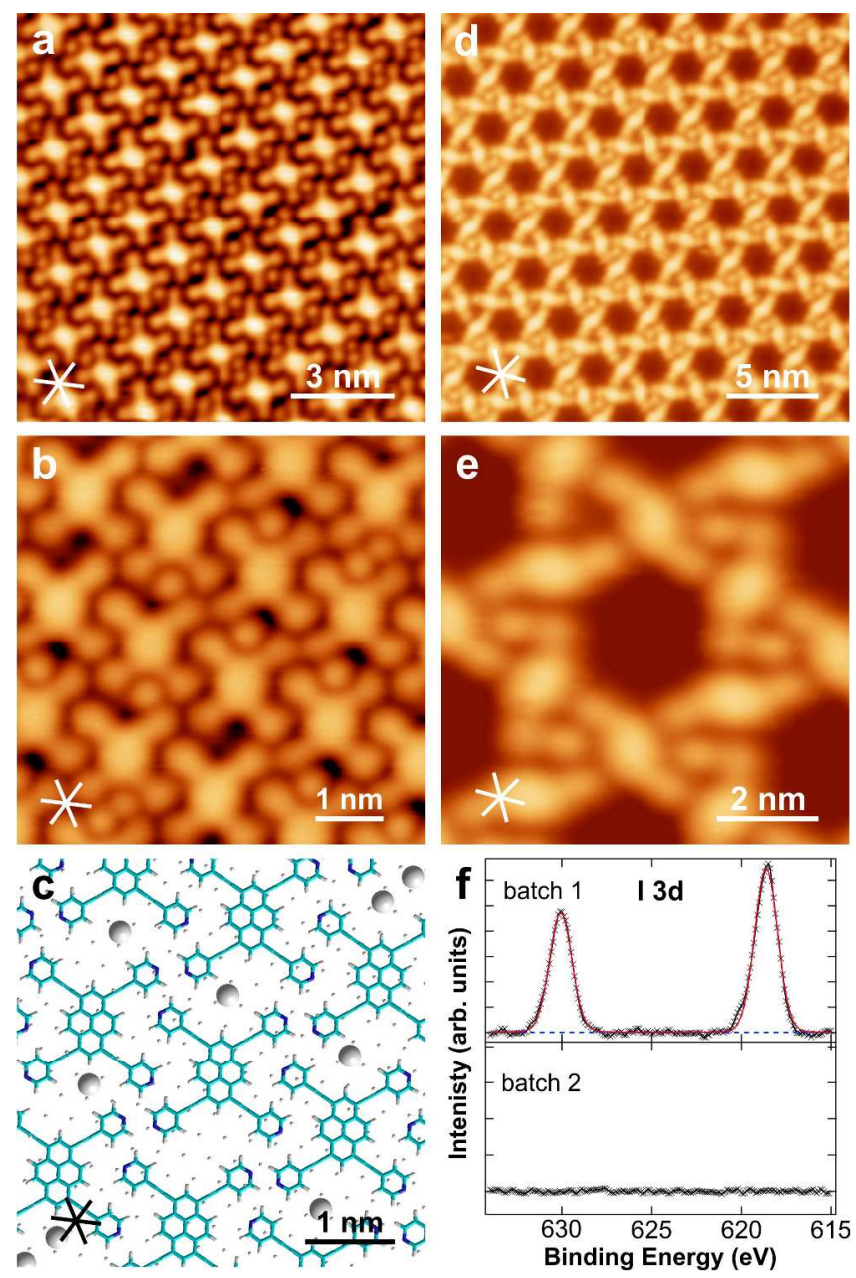

Figure 6. Self-assembly of pyridyl-terminated pyrene species 1 and 2 on $\operatorname{Ag}(111)$ showing decoration by co-adsorbed iodide. (a,b,c) Rhombic islands formed by species 1. (a) Overview image $(0.05 \mathrm{nA}, 1 \mathrm{~V})$. (b) High-resolution image showing the protrusions attributed to iodide 
species $(0.05 \mathrm{nA},-1 \mathrm{~V})$. (c) Tentative model of a detail of (b) highlighting the plausible hollow site adsorption of iodide. (d,e) Kagomé lattice formed by species 2. (d) Overview image (0.1 nA, $-0.2 \mathrm{~V})$. (e) High resolution image $(0.09 \mathrm{nA}, 0.1 \mathrm{~V})$. (f) Iodine $3 \mathrm{~d}$ XPS signature of the Icontaminated (top) and clean (bottom) samples of molecule $\mathbf{1}$.

In the case of tetradentated module $\mathbf{1}$, the small voids can be filled with either zero, one or two iodide units (Figures 6a,b), whereas in the case of the kagomé lattice only one iodide is accommodated (Figures 6d,e). The large cavities rarely exhibit a single protrusion tucked into one of the six corners. Island borders are not decorated in any case, which suggests that the iodide maximizes its interaction with adjacent pyrene molecules by occupying the pores. Below the saturation coverage of the small cavities (2 I per 1; 2/3 I per 2 ), the hosted iodide has a minor influence on the porous architectures. While the rhombic network of module 1 shows unit cell vector $\mathrm{a}_{2}$ to be slightly extended by less than $1 \AA$, the kagomé's unit cell appears not to be changed. Structural models based on the high-resolution STM data highlight the positions of the iodide atoms relative to the pyrenes (Figure $6 \mathrm{c}$ ). The substrate registry was chosen in a way to accommodate the iodide on the well-known hollow adsorption sites of the $\operatorname{Ag}(111)$ lattice. ${ }^{85}$ The resulting average $\mathrm{I} \cdots \mathrm{H}$ distance amounts to $(2.9 \pm 0.5) \AA$, which is slightly smaller than the sum of the van der Waals radii of the two atoms $(3.18 \AA)$, consistent with attractive interactions. Indeed, differences in electronegativity between halogens ${ }^{86}$ or diatomic adsorbates ${ }^{87}$ and hydrogens are known to stabilize supramolecular architectures on surfaces. However, comparing the distances between two adjacent modules 1 separated by zero, one or two iodides, only a minute difference of less than $0.5 \AA$ - well within the error bar of our measurements - is observed. This suggests that the iodide residence in the pore ${ }^{88}$ is determined by the availability of preferred hollow adsorption sites within the voids. As visualized in Figure 6c, due to the non- 
commensurate overlayer structure, every pore exposes different bare Ag areas. In most pores, one hollow site is available within the steric constraints, while some pores offer two hollow sites with a separation exceeding twice the van der Waals radius of the iodide units. In the case of the kagomé lattice formed from $\mathbf{2}$, the registry is consistent with small pores being centered on hollow sites (Figure 6d), thus hosting a maximum of one iodide each. A further increase of iodine leads to a rearrangement of the architectures featuring iodides on all four sides of the modules 1 (SI Figure SI5). In agreement with the literature discussing the thermal desorption of iodine from $\operatorname{Ag}(111),{ }^{89}$ moderate annealing to $180^{\circ} \mathrm{C}$ did not induce a significant decrease of the iodide species in the pyrene architectures.

\section{CONCLUSION}

In summary, we have introduced the synthesis and the self-assembly abilities of a family of pyrene derivatives peripherally functionalized with pyridin-4-ylethynyl termini. The deliberate geometrical positioning of the pyridyl recognition sites in a tetra- (1), trans- (2) or cis-like fashion (3) allows the tailoring of different supramolecular architectures, giving rise to rhombic arrays (1), "knitted" porous kagomé networks (2) and "crocheted" chain-like assemblies (3). The intermolecular $\mathrm{N} \cdots \mathrm{H}$ bonds - enabled by the pyridyl termini - proved to be decisive for the formation of the supramolecular structures. For the phenyl-functionalized reference pyrenes (1a, 2a and 3a), repulsive intermolecular interactions dominate, resulting in individual modules at low coverage. Importantly, our work thus provides two new aspects. First, we introduce programmed pyrene derivative yielding means to position pyrenes in distinct patterns on smooth surfaces. Previous studies based on direct functionalization of the pyrene core, e.g., by halogenation, only report on dense-packed two-dimensional arrays or disordered networks. 
Second, by introducing ethynyl links in our new family of pyrenes, the functional characteristics of the pyrene core can be decoupled from the terminal moieties guiding the self-assembly properties. A combination of these two features will be specifically relevant when designing nanostructures with tailored optoelectronic characteristics on insulating supports. Indeed, we provided a proof of principle for the successful formation of regular pyrene arrays on an insulating h-BN monolayer supported on $\mathrm{Cu}(111)$. Furthermore, we have exploited the open porous architectures of modules $\mathbf{1}$ and $\mathbf{2}$ as templates for the spangling with individual monoatomic iodine guests, identified as iodides by XPS. Their positioning is tentatively assigned to a preferred adsorption on the hollow sites of the $\operatorname{Ag}(111)$ substrate, where they do not interfere with the order of the pyrene arrays at moderate coverage. The decoration of supramolecular networks with iodide units that bases on attractive interactions might thus be instrumental in stabilizing the selected organic architectures, displaying exceptional hosting capabilities of the porous network. To conclude, we introduced a new pyrene family via a systematic functionalization with pyridyl termini and demonstrated its potential by assembling a variety of distinct supramolecular structures with customized topology. We anticipate that the intermolecular interactions detailed in this study will permit to assemble highly ordered pyrene architectures on advanced substrates, as thin films, hybrid structures or insulators, thus opening up pathways to fully exploit their optoelectronic properties.

\section{METHODS}

All experiments were performed using a custom-built ultrahigh vacuum system housing an SPS-CreaTec low-temperature STM operated at $6 \mathrm{~K}$. The base pressure was in the range of $\sim 8 \mathrm{x}$ $10^{-10}$ mbar during deposition. The Ag(111) single crystal was cleaned by repeated $\mathrm{Ar}^{+}$sputtering 
cycles at $800 \mathrm{eV}$ and subsequent annealing at $723 \mathrm{~K}$ for 10 minutes. Subsequently, the pyrene derivatives were deposited by organic molecular beam epitaxy from a thoroughly degassed quartz crucible held at varying temperatures onto the $\mathrm{Ag}(111)$ surface held at $\sim 300 \mathrm{~K}$.

All STM images were acquired in constant current mode using an electrochemically etched tungsten tip prepared by $\mathrm{Ar}^{+}$sputtering at $1 \mathrm{keV}$ and controlled tip-formings into the bare $\operatorname{Ag}(111)$ surface. The structural models were generated using the HyperChem 7.5 Software package, whereas the WSxM software was used represent the STM images.

The XP spectra were taken under ultrahigh vacuum conditions with a base pressure in the low $10^{-9}$ mbar regime. The single crystal $\mathrm{Ag}(111)$ surface was cleaned by combination of $\mathrm{Ar}^{+}$ sputtering $(1 \mathrm{keV})$ and annealing at $720 \mathrm{~K}$. The pyrene derivate was deposited by organic molecular beam epitaxy from a boron nitride crucible held at $590 \mathrm{~K}$ onto the substrate, which was held at room temperature. All measurements were performed at room temperature. The spectra were taken in normal electron emission geometry and the pass energy for the hemispherical analyzer was set to $20 \mathrm{eV}$. The electrons were excited by X-ray emission from a polychromic $\mathrm{Al} \mathrm{K}$ source. All binding energies were calibrated according to the $\mathrm{Ag} 3 \mathrm{~d} 5 / 2$ line $(368.3 \mathrm{eV})$ of the substrate. The linear background was subtracted from the raw data using either a Shirley background (C 1s) or polynomial functions (I 3d) and afterwards the spectra were fitted using a Voigt function.

Characterizations of compounds $4,,^{90} \mathbf{5},,^{90} \mathbf{6},,^{11} \mathbf{7}^{92} \mathbf{8}^{93}$ and $\mathbf{9}^{92}$ were in accordance with literature. Melting points are uncorrected. ${ }^{1} \mathrm{H}$ and ${ }^{13} \mathrm{C}$ NMR spectra were measured using a Varian Inova spectrometer at 500 and $125 \mathrm{MHz}$, respectively. Chemical shifts are reported in parts per million (ppm) and are referenced to the residual solvent peak. Coupling constants $(J)$ are given in Hertz $(\mathrm{Hz})$. IR spectra $(\mathrm{KBr})$ were recorded on a Perkin Elmer 2000 spectrometer. 
(HR)-MALDI-MS mass spectrometry was performed by the Centre de spectrométrie de masse at the Université de Mons in Belgium recorded using a Waters QToF Premier mass spectrometer.

\section{ASSOCIATED CONTENT}

Supporting Information. Synthetic procedures and complete characterization of compounds 1-3 and 1a-3a. Additional STM images and analysis of intermolecular distances. C 1s XPS data of compound 1. This material is available free of charge via the Internet at http://pubs.acs.org.

\section{AUTHOR INFORMATION}

Corresponding Author

*wau@,tum.de

*david.ecija@tum.de

*BonifaziD@cardiff.ac.uk

\section{Author Contributions}

The manuscript was written through contributions of all authors. All authors have given approval to the final version of the manuscript.

\section{ACKNOWLEDGMENT}

This work was supported by the European Research Council Advanced Grant MolArt $\left(\mathrm{n}^{\circ}\right.$ 247299) and the Munich-Center for Advanced Photonics (MAP). DB gratefully acknowledges the EU through the ERC Starting Grant "COLORLANDS", the FRS-FNRS (FRFC contracts $n^{\circ}$ 
2.4.550.09), the MIUR through the FIRB Futuro in Ricerca "SUPRACARBON" (contract $n^{\circ}$ RBFR10DAK6). AW was supported by the International Max Planck Research School of Advanced Photon Science (IMPRS-APS). DE is grateful for financial support from the EU (EC FP7-PEOPLE-2011-COFUND AMAROUT II program) and the Spanish Ministerio de Economía y Competitividad (MINECO) (project RYC-2012-11133). WA acknowledges funding by the DFG via a Heisenberg professorship and by the European Research Council Consolidator Grant NanoSurfs (n 615233).

\section{References}

1. Jain, A.; George, S. J., New Directions in Supramolecular Electronics. Mater. Today 2015, 18, 206-214.

2. Joachim, C.; Gimzewski, J. K.; Aviram, A., Electronics Using Hybrid-Molecular and Mono-Molecular Devices. Nature 2000, 408, 541-548.

3. Ortmann, F.; Radke, K. S.; Günther, A.; Kasemann, D.; Leo, K.; Cuniberti, G., Materials Meets Concepts in Molecule-Based Electronics. Adv. Funct. Mater. 2015, 25, 1933-1954.

4. Schenning, A. P.; Meijer, E. W., Supramolecular Electronics; Nanowires from SelfAssembled Pi-Conjugated Systems. Chem. Commun. 2005, 3245-3258.

5. Lehn, J.-M., Supramolecular Chemistry: Concepts and Perspectives. Wiley-VCH: Weinheim, 1995.

6. Lehn, J. M., Toward Self-Organization and Complex Matter. Science 2002, 295, 24002403.

7. Whitesides, G. M.; Grzybowski, B., Self-Assembly at All Scales. Science 2002, 295, 2418-2421.

8. Orgiu, E.; Samori, P., 25th Anniversary Article: Organic Electronics Marries Photochromism: Generation of Multifunctional Interfaces, Materials, and Devices. Adv. Mater. 2014, 26, 1827-1845.

9. Otero, R.; Gallego, J. M.; de Parga, A. L.; Martin, N.; Miranda, R., Molecular SelfAssembly at Solid Surfaces. Adv. Mater. 2011, 23, 5148-5176.

10. Elemans, J. A.; Lei, S.; De Feyter, S., Molecular and supramolecular networks on surfaces: from two-dimensional crystal engineering to reactivity. Angew. Chem. Int. Ed. 2009, 48, 7298-7332.

11. Barth, J. V., Molecular Architectonic on Metal Surfaces. Annu. Rev. Phys. Chem. 2007, 58, 375-407. 
12. Bonifazi, D.; Mohnani, S.; Llanes-Pallas, A., Supramolecular Chemistry at Interfaces: Molecular Recognition on Nanopatterned Porous Surfaces. Chem. Eur. J. 2009, 15, 70047025.

13. Ciesielski, A.; Samori, P., Supramolecular Assembly/Reassembly Processes: Molecular Motors and Dynamers Operating at Surfaces. Nanoscale 2011, 3, 1397-1410.

14. Barth, J. V.; Costantini, G.; Kern, K., Engineering Atomic and Molecular Nanostructures at Surfaces. Nature 2005, 437, 671-679.

15. Becker, C.; Wandelt, K., Surfaces: Two-Dimensional Templates. Top. Curr. Chem. 2009, 287, 45-86.

16. Samorì, P., Scanning Probe Microscopies Beyond Imaging. Wiley-VCH: Weinheim, 2006.

17. Seufert, K.; Auwärter, W.; Barth, J. V., Discriminative Response of Surface-Confined Metalloporphyrin Molecules to Carbon and Nitrogen Monoxide. J. Am. Chem. Soc. 2010, 132, 18141-18146.

18. Wäckerlin, C.; Chylarecka, D.; Kleibert, A.; Müller, K.; Iacovita, C.; Nolting, F.; Jung, T. A.; Ballav, N., Controlling Spins in Adsorbed Molecules by a Chemical Switch. Nat. Commun. 2010, $1,61$.

19. Besenbacher, F.; Lauritsen, J. V.; Linderoth, T. R.; Lægsgaard, E.; Vang, R. T.; Wendt, S., Atomic-Scale Surface Science Phenomena Studied by Scanning Tunneling Microscopy. Surf. Sci. 2009, 603, 1315-1327.

20. Baddeley, C. J., Fundamental Investigations of Enantioselective Heterogeneous Catalysis. Top. Catal. 2003, 25, 17-28.

21. Leoni, T.; Guillermet, O.; Walch, H.; Langlais, V.; Scheuermann, A.; Bonvoisin, J.; Gauthier, S., Controlling the Charge State of a Single Redox Molecular Switch. Phys. Rev. Lett. 2011, 106, 216103.

22. de Oteyza, D. G.; Gorman, P.; Chen, Y. C.; Wickenburg, S.; Riss, A.; Mowbray, D. J.; Etkin, G.; Pedramrazi, Z.; Tsai, H. Z.; Rubio, A.; Crommie, M. F.; Fischer, F. R., Direct Imaging of Covalent Bond Structure in Single-Molecule Chemical Reactions. Science 2013, 340, 1434-1437.

23. Chakrabarty, R.; Mukherjee, P. S.; Stang, P. J., Supramolecular Coordination: SelfAssembly of Finite Two- and Three-Dimensional Ensembles. Chem. Rev. 2011, 111, 6810-6918.

24. Cook, T. R.; Stang, P. J., Recent Developments in the Preparation and Chemistry of Metallacycles and Metallacages via Coordination. Chem. Rev. 2015, 115, 7001-7045.

25. Ding, S. Y.; Wang, W., Covalent Organic Frameworks (COFs): From Design to Applications. Chem. Soc. Rev. 2013, 42, 548-568.

26. Palma, C. A.; Cecchini, M.; Samorì, P., Predicting Self-Assembly: From Empirism to Determinism. Chem. Soc. Rev. 2012, 41, 3713-3730.

27. Ward, M. D.; Raithby, P. R., Functional Behaviour From Controlled Self-Assembly: Challenges and Prospects. Chem. Soc. Rev. 2013, 42, 1619-1636.

28. Klyatskaya, S.; Klappenberger, F.; Schlickum, U.; Kühne, D.; Marschall, M.; Reichert, J.; Decker, R.; Krenner, W.; Zoppellaro, G.; Brune, H., Surface-Confined Self-Assembly of Di-carbonitrile Polyphenyls. Adv. Funct. Mater. 2011, 21, 1230-1240.

29. Fendt, L. A.; Stöhr, M.; Wintjes, N.; Enache, M.; Jung, T. A.; Diederich, F., Modification of Supramolecular Binding Motifs Induced by Substrate Registry: Formation of SelfAssembled Macrocycles and Chain-Like Patterns. Chem. Eur. J. 2009, 15, 11139-11150. 
30. Yokoyama, T.; Yokoyama, S.; Kamikado, T.; Okuno, Y.; Mashiko, S., Selective Assembly on a Surface of Supramolecular Aggregates with Controlled Size and Shape. Nature 2001, 413, 619-621.

31. Urgel, J. I.; Écija, D.; Auwärter, W.; Stassen, D.; Bonifazi, D.; Barth, J. V., Orthogonal Insertion of Lanthanide and Transition-Metal Atoms in Metal-Organic Networks on Surfaces. Angew. Chem. Int. Ed. 2015, 54, 6163-6167.

32. Lin, T.; Wu, Q.; Liu, J.; Shi, Z.; Liu, P. N.; Lin, N., Thermodynamic Versus Kinetic Control in Self-Assembly of Zero-, One-, Quasi-Two-, and Two-Dimensional MetalOrganic Coordination Structures. J. Chem. Phys. 2015, 142, 101909.

33. Li, Y.; Xiao, J.; Shubina, T. E.; Chen, M.; Shi, Z.; Schmid, M.; Steinrück, H.-P.; Gottfried, J. M.; Lin, N., Coordination and Metalation Bifunctionality of $\mathrm{Cu}$ with 5,10,15,20-Tetra(4-pyridyl)porphyrin: Toward a Mixed-Valence Two-Dimensional Coordination Network. J. Am. Chem. Soc. 2012, 134, 6401-6408.

34. Auwärter, W.; Écija, D.; Klappenberger, F.; Barth, J. V., Porphyrins at Interfaces. Nat. Chem. 2015, 7, 105-120.

35. Gottfried, J. M., Surface Chemistry of Porphyrins and Phthalocyanines. Surf. Sci. Rep. 2015, 70, 259-379.

36. Heim, D.; Écija, D.; Seufert, K.; Auwärter, W.; Aurisicchio, C.; Fabbro, C.; Bonifazi, D.; Barth, J. V., Self-Assembly of Flexible One-Dimensional Coordination Polymers on Metal Surfaces. J. Am. Chem. Soc. 2010, 132, 6783-6790.

37. Heim, D.; Seufert, K.; Auwärter, W.; Aurisicchio, C.; Fabbro, C.; Bonifazi, D.; Barth, J. V., Surface-Assisted Assembly of Discrete Porphyrin-Based Cyclic Supramolecules. Nano Lett. 2010, 10, 122-128.

38. Urgel, J. I.; Schwarz, M.; Garnica, M.; Stassen, D.; Bonifazi, D.; Écija, D.; Barth, J. V.; Auwärter, W., Controlling Coordination Reactions and Assembly on a $\mathrm{Cu}(111)$ Supported Boron Nitride Monolayer. J. Am. Chem. Soc. 2015, 137, 2420-2423.

39. Grimsdale, A. C.; Müllen, K., The Chemistry of Organic Nanomaterials. Angew. Chem. Int. Ed. 2005, 44, 5592-5629.

40. Wang, C.; Dong, H.; Hu, W.; Liu, Y.; Zhu, D., Semiconducting Pi-Conjugated Systems in Field-Effect Transistors: a Material Odyssey of Organic Electronics. Chem. Rev. 2012, 112, 2208-2267.

41. Narita, A.; Wang, X. Y.; Feng, X.; Müllen, K., Accounts of Chemical ResearchNew Advances in Nanographene Chemistry. Chem. Soc. Rev. 2015, 44, 6616-6643.

42. Figueira-Duarte, T. M.; Müllen, K., Pyrene-Based Materials for Organic Electronics. Chem. Rev. 2011, 111, 7260-7314.

43. Park, Y. H.; Rho, H. H.; Park, N. G.; Kim, Y. S., Theoretical Investigation of TetraSubstituted Pyrenes for Organic Light Emitting Diodes. Curr. Appl. Phys. 2006, 6, 691694.

44. Uno, S.; Dohno, C.; Bittermann, H.; Malinovskii, V. L.; Haner, R.; Nakatani, K., A Light-Driven Supramolecular Optical Switch. Angew. Chem. Int. Ed. 2009, 48, 73627365.

45. Casas-Solvas, J. M.; Howgego, J. D.; Davis, A. P., Synthesis of Substituted Pyrenes by Indirect Methods. Org. Biomol. Chem. 2014, 12, 212-232.

46. Malinovskii, V. L.; Samain, F.; Haner, R., Helical Arrangement of Interstrand Stacked Pyrenes in a DNA Framework. Angew. Chem. Int. Ed. 2007, 46, 4464-4467.

47. Birks, J. B., Excimers. Rep. Prog. Phys. 1975, 38, 904-974. 
48. Ramakrishna Matte, H. S. S.; Subrahmanyam, K. S.; Venkata Rao, K.; George, S. J.; Rao, C. N. R., Quenching of Fluorescence of Aromatic Molecules by Graphene due to Electron Transfer. Chem. Phys. Lett. 2011, 506, 260-264.

49. Lee, O. P.; Yiu, A. T.; Beaujuge, P. M.; Woo, C. H.; Holcombe, T. W.; Millstone, J. E.; Douglas, J. D.; Chen, M. S.; Fréchet, J. M. J., Efficient Small Molecule Bulk Heterojunction Solar Cells with High Fill Factors via Pyrene-Directed Molecular SelfAssembly. Adv. Mater. 2011, 23, 5359-5363.

50. Pham, T. A.; Song, F.; Nguyen, M.-T.; Stöhr, M., Self-Assembly of Pyrene Derivatives on $\mathrm{Au}(111)$ : Substituent Effects on Intermolecular Interactions. Chem. Commun. 2014, 50, 14089-14092.

51. Llanes-Pallas, A.; Palma, C.-A.; Piot, L.; Belbakra, A.; Listorti, A.; Prato, M.; Samorì, P.; Armaroli, N.; Bonifazi, D., Engineering of Supramolecular H-Bonded Nanopolygons via Self-Assembly of Programmed Molecular Modules. J. Am. Chem. Soc. 2009, 131, 509520.

52. Piot, L.; Palma, C.-A.; Llanes-Pallas, A.; Prato, M.; Szekrényes, Z.; Kamarás, K.; Bonifazi, D.; Samorì, P., Selective Formation of Bi-Component Arrays Through HBonding of Multivalent Molecular Modules. Adv. Funct. Mater. 2009, 19, 1207-1214.

53. Della Pia, A.; Riello, M.; Floris, A.; Stassen, D.; Jones, T. S.; Bonifazi, D.; De Vita, A.; Costantini, G., Anomalous Coarsening Driven by Reversible Charge Transfer at MetalOrganic Interfaces. ACS Nano 2014, 8, 12356-12364.

54. Zhao, H. L.; Zhang, S.; Li, S.; Song, X.; Liu, W.; Liu, B.; Dong, M. D., Investigation of the Non-Covalent Interactions of Molecular Self-Assembly by Scanning Tunneling Microscopy Using the Association of Aromatic Structures in Pyrene-4,5,9,10-Tetraone and Phenanthrene-9,10-Dione Molecules. RSC Adv. 2015, 5, 103316-103320.

55. Pham, T. A.; Song, F.; Nguyen, M. T.; Li, Z.; Studener, F.; Stöhr, M., Comparing Ullmann Coupling on Noble Metal Surfaces: On-Surface Polymerization of 1, 3, 6, 8Tetrabromopyrene on $\mathrm{Cu}$ (111) and $\mathrm{Au}$ (111). Chem. Eur. J. 2016, 22, 5937-5944.

56. Écija, D.; Seufert, K.; Heim, D.; Auwärter, W.; Aurisicchio, C.; Fabbro, C.; Bonifazi, D.; Barth, J. V., Hierarchic Self-Assembly of Nanoporous Chiral Networks with Conformationally Flexible Porphyrins. ACS Nano 2010, 4, 4936-4942.

57. Yoosaf, K.; Llanes-Pallas, A.; Marangoni, T.; Belbakra, A.; Marega, R.; Botek, E.; Champagne, B.; Bonifazi, D.; Armaroli, N., From Molecular to Macroscopic Engineering: Shaping Hydrogen-Bonded Organic Nanomaterials. Chem. Eur. J. 2011, 17, 3262-3273.

58. Zeitouny, J.; Belbakra, A.; Llanes-Pallas, A.; Barbieri, A.; Armaroli, N.; Bonifazi, D., On the Route to Mimic Natural Movements: Synthesis and Photophysical Properties of a Molecular Arachnoid. Chem. Commun. 2011, 47, 451-453.

59. Marangoni, T.; Mezzasalma, S. A.; Llanes-Pallas, A.; Yoosaf, K.; Armaroli, N.; Bonifazi, D., Thermosolutal Self-Organization of Supramolecular Polymers into Nanocraters. Langmuir 2011, 27, 1513-1523.

60. Chinchilla, R.; Najera, C., Recent Advances in Sonogashira Reactions. Chem. Soc. Rev. 2011, 40, 5084-5121.

61. Sonogashira, K.; Tohda, Y.; Hagihara, N., A Convenient Synthesis of Acetylenes: Catalytic Substitutions of Acetylenic Hydrogen with Bromoalkenes, Iodoarenes and Bromopyridines. Tetrahedron Lett. 1975, 16, 4467-4470. 
62. Chinchilla, R.; Najera, C., The Sonogashira Reaction: A Booming Methodology in Synthetic Organic Chemistry. Chem. Rev. 2007, 107, 874-922.

63. Held, G., Low-Energy Electron Diffraction Crystallography of Surfaces and Interfaces. Bunsen-Mag. 2010, 12, 124-131.

64. Bischoff, F.; Seufert, K.; Auwärter, W.; Joshi, S.; Vijayaraghavan, S.; Écija, D.; Diller, K.; Papageorgiou, A. C.; Fischer, S.; Allegretti, F.; Duncan, D. A.; Klappenberger, F.; Blobner, F.; Han, R.; Barth, J. V., How Surface Bonding and Repulsive Interactions Cause Phase Transformations: Ordering of a Prototype Macrocyclic Compound on Ag(111). ACS Nano 2013, 7, 3139-3149.

65. Gross, L.; Moresco, F.; Ruffieux, P.; Gourdon, A.; Joachim, C.; Rieder, K.-H., Tailoring Molecular Self-Organization by Chemical Synthesis: Hexaphenylbenzene, Hexa-PeriHexabenzocoronene, and Derivatives on $\mathrm{Cu}$ (111). Phys. Rev. B 2005, 71, 165428.

66. Yoshida, Y.; Yang, H.-H.; Huang, H.-S.; Guan, S.-Y.; Yanagisawa, S.; Yokosuka, T.; Lin, M.-T.; Su, W.-B.; Chang, C.-S.; Hoffmann, G.; Hasegawa, Y., Scanning Tunneling Microscopy/Spectroscopy of Picene Thin Films Formed on $\operatorname{Ag}(111)$. J. Chem. Phys. 2014, 141, 114701.

67. Tseng, T.-C.; Urban, C.; Wang, Y.; Otero, R.; Tait, S. L.; Alcamí, M.; Écija, D.; Trelka, M.; Gallego, J. M.; Lin, N.; Konuma, M.; Starke, U.; Nefedov, A.; Langner, A.; Wöll, C.; Herranz, M. Á.; Martín, F.; Martín, N.; Kern, K.; Miranda, R., Charge-Transfer-Induced Structural Rearrangements at Both Sides of Organic/Metal Interfaces. Nat. Chem. 2010, 2, 374-379.

68. Furukawa, S.; Uji-i, H.; Tahara, K.; Ichikawa, T.; Sonoda, M.; De Schryver, F. C.; Tobe, Y.; De Feyter, S., Molecular Geometry Directed Kagome and Honeycomb Networks: Toward Two-Dimensional Crystal Engineering. J. Am. Chem. Soc. 2006, 128, 35023503.

69. Mao, J. H.; Zhang, H. G.; Jiang, Y. H.; Pan, Y.; Gao, M.; Xiao, W. D.; Gao, H. J., Tunability of Supramolecular Kagome Lattices of Magnetic Phthalocyanines Using Graphene-Based Moire Patterns as Templates. J. Am. Chem. Soc. 2009, 131, 1413614137.

70. Schlickum, U.; Decker, R.; Klappenberger, F.; Zoppellaro, G.; Klyatskaya, S.; Auwärter, W.; Neppl, S.; Kern, K.; Brune, H.; Ruben, M.; Barth, J. V., Chiral Kagomé Lattice from Simple Ditopic Molecular Bricks. J. Am. Chem. Soc. 2008, 130, 11778-11782.

71. Metrangolo, P.; Neukirch, H.; Pilati, T.; Resnati, G., Halogen Bonding Based Recognition Processes: A World Parallel to Hydrogen Bonding. Acc. Chem. Res. 2005, 38, 386-395.

72. Jentzsch, A. V.; Emery, D.; Mareda, J.; Metrangolo, P.; Resnati, G.; Matile, S., Ditopic Ion Transport Systems: Anion-p Interactions and Halogen Bonds at Work. Angew. Chem. Int. Ed. 2011, 50, 11675-11678.

73. Walch, H.; Gutzler, R.; Sirtl, T.; Eder, G.; Lackinger, M., Material- and OrientationDependent Reactivity for Heterogeneously Catalyzed Carbon-Bromine Bond Homolysis. J. Phys. Chem. C 2010, 114, 12604-12609.

74. Fan, Q.; Wang, C.; Liu, L.; Han, Y.; Zhao, J.; Zhu, J.; Kuttner, J.; Hilt, G.; Gottfried, J. M., Covalent, Organometallic, and Halogen-Bonded Nanomeshes from TetrabromoTerphenyl by Surface-Assisted Synthesis on $\mathrm{Cu}$ (111). J. Phys. Chem. C 2014, 118, 13018-13025. 
75. Lipton-Duffin, J.; Ivasenko, O.; Perepichka, D.; Rosei, F., Synthesis of Polyphenylene Molecular Wires by Surface-Confined Polymerization. Small 2009, 5, 592-597.

76. Wang, W.; Shi, X.; Wang, S.; Van Hove, M. A.; Lin, N., Single-Molecule Resolution of an Organometallic Intermediate in a Surface-Supported Ullmann Coupling Reaction. $J$. Am. Chem. Soc. 2011, 133, 13264-13267.

77. Eichhorn, J.; Strunskus, T.; Rastgoo-Lahrood, A.; Samanta, D.; Schmittel, M.; Lackinger, M., On-Surface Ullmann Polymerization via Intermediate Organometallic Networks on Ag(111). Chem. Commun. 2014, 50, 7680-7682.

78. Gaarenstroom, S.; Winograd, N., Initial and Final State Effects in the ESCA Spectra of Cadmium and Silver Oxides. J. Chem. Phys. 1977, 67, 3500-3506.

79. Moers, H.; Klewe-Nebenius, H.; Pfennig, G.; Ache, H., Untersuchungen zur Wechselwirkung von Gasförmigem Molekularem Iod mit Silberoberflächen mittels XPS und AES. Fres. J. Anal. Chem. 1987, 329, 361-366.

80. Sherwood, P. M., X-ray Photoelectron Spectroscopic Studies of Some Iodine Compounds. J. Chem. Soc., Faraday Trans. 2 1976, 72, 1805-1820.

81. Castro, M. E.; Pressley, L. A.; Kiss, J.; Pylant, E. D.; Jo, S. K.; Zhou, X. L.; White, J. M., Adsorption and Decomposition of Trifluoroiodomethane on Clean and Iodine-Precovered Ag(111). J. Phys. Chem. 1993, 97, 8476-8484.

82. Wertheim, G. K.; Dicenzo, S. B.; Buchanan, D. N. E., Core-Electron Spectroscopy of Adsorbate Ions - Iodine on Ag(111). Phys. Rev. B 1982, 25, 3020-3025.

83. Antczak, G.; Kamiński, W.; Morgenstern, K., Stabilizing CuPc Coordination Networks on Ag (100) by Ag Atoms. J. Phys. Chem. C 2015, 119, 1442-1450.

84. Rais, D.; Mingos, D. M. P.; Vilar, R.; White, A. J.; Williams, D. J., Pi-Coordination of Silver and Copper to Mercury Bis-Alkynyls: Synthesis and Structural Characterization. Organometallics 2000, 19, 5209-5217.

85. Forstmann, F.; Berndt, W.; Büttner, P., Determination of the Adsorption Site by LowEnergy Electron Diffraction for Iodine on Silver (111). Phys. Rev. Lett. 1973, 30, 17-19.

86. Park, J.; Kim, K. Y.; Chung, K.-H.; Yoon, J. K.; Kim, H.; Han, S.; Kahng, S.-J., Interchain Interactions Mediated by $\mathrm{Br}$ Adsorbates in Arrays of Metal-Organic Hybrid Chains on Ag (111). J. Phys. Chem. C 2011, 115, 14834-14838.

87. Buchner, F.; Seufert, K.; Auwärter, W.; Heim, D.; Barth, J. V.; Flechtner, K.; Gottfried, J. M.; Steinrück, H.-P.; Marbach, H., NO-Induced Reorganization of Porphyrin Arrays. ACS Nano 2009, 3, 1789-1794.

88. Fan, Q.; Wang, C.; Liu, L.; Han, Y.; Zhao, J.; Zhu, J.; Kuttner, J.; Hilt, G.; Gottfried, J. M., Covalent, Organometallic, and Halogen-Bonded Nanomeshes from TetrabromoTerphenyl by Surface-Assisted Synthesis on $\mathrm{Cu}$ (111). J. Phys. Chem. C 2014, 118, 13018-13025.

89. Bardi, U.; Rovida, G., LEED, AES and Thermal Desorption Study of Iodine Chemisorption on the Silver (100),(111) and (110) Faces. Surf. Sci. 1983, 128, 145-168.

90. Bernhardt, S.; Kastler, M.; Enkelmann, V.; Baumgarten, M.; Müllen, K., Pyrene as Chromophore and Electrophore: Encapsulation in a Rigid Polyphenylene Shell. Chem. Eur. J. 2006, 12, 6117-6128.

91. Maeda, H.; Maeda, T.; Mizuno, K.; Fujimoto, K.; Shimizu, H.; Inouye, M., Alkynylpyrenes as Improved Pyrene-Based Biomolecular Probes with the Advantages of High Fluorescence Quantum Yields and Long Absorption/Emission Wavelengths. Chem. Eur. J. 2006, 12, 824-831. 
92. Ji, S. M.; Yang, J.; Yang, Q.; Liu, S. S.; Chen, M. D.; Zhao, J. Z., Tuning the Intramolecular Charge Transfer of Alkynylpyrenes: Effect on Photophysical Properties and Its Application in Design of OFF-ON Fluorescent Thiol Probes. J. Org. Chem. 2009, 74, 4855-4865.

93. Leroy-Lhez, S.; Fages, F., Synthesis and Photophysical Properties of a Highly Fluorescent Ditopic Ligand Based on 1,6-Bis(Ethynyl)Pyrene as Central Aromatic Core. Eur. J. Org. Chem. 2005, 2684-2688.

TOC graphic:

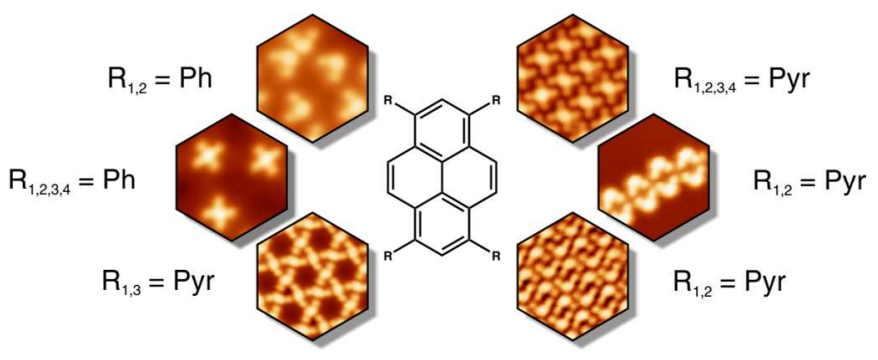

